\title{
Phytophthora pluvialis Studies on Douglas-fir Require Swiss Needle Cast Suppression
}

\author{
Mireia Gómez-Gallego and Martin Karl-Friedrich Bader, Institute for Applied Ecology New Zealand, School of Science, Auckland Uni- \\ versity of Technology, Auckland 1142, New Zealand; and New Zealand Forest Research Institute (Scion), Te Papa Tipu Innovation Park, \\ Rotorua 3046, New Zealand; Peter Matthew Scott, New Zealand Forest Research Institute (Scion), Te Papa Tipu Innovation Park, Rotorua \\ 3046, New Zealand; Sebastian Leuzinger, Institute for Applied Ecology New Zealand, School of Science, Auckland University of Technol- \\ ogy, Auckland 1142, New Zealand; and Nari Michelle Williams, New Zealand Forest Research Institute (Scion), Te Papa Tipu Innovation \\ Park, Rotorua 3046, New Zealand
}

\begin{abstract}
Phytophthora pluvialis is associated with early defoliation and shoot dieback in Douglas-fir in Oregon and New Zealand. In 2013, P. pluvialis was described from mixed tanoak-Douglas-fir forests in the Pacific Northwest and concurrently recognized as the main causal agent of red needle cast (RNC) in New Zealand radiata pine plantations. Little is known about its infection cycle and impact on host physiology. P. pluvialis studies in Douglas-fir are challenging due to the ubiquitous presence of the endophyte Phaeocryptopus gaeumannii, which produces similar symptoms and premature defoliation with persistent needle wetness, known as Swiss needle cast

(SNC). Nonetheless, our study showed $P$. pluvialis infection in the presence of SNC. Exclusive expression of $P$. pluvialis is difficult to achieve as both diseases are promoted by high humidity. Here we established a 'dry leaf' strategy to suppress SNC when inoculating Douglas-fir needles for RNC studies. Sheltering plants along with drip irrigation to avoid needle wetness during the $P$. gaeumannii sporulation period suppressed its development in the new season flush. The diminished endophyte inoculum enabled bias-reduced studies of $P$. pluvialis impacts on Douglas-fir without the confounding effects of stomatal blockage and premature defoliation caused by $P$. gaeumannii.
\end{abstract}

Phytophthora pluvialis Reeser, Sutton, and Hansen has been shown to be the main causal agent of red needle cast (RNC) in radiata pine (Pinus radiata [D. Don]) plantations in New Zealand noted since 2008 (Dick et al. 2014). This oomycete was first isolated from baited streams, soil, and canopy drip in mixed tanoak-Douglas-fir forests in Oregon, where it is believed to be endemic with multiple hosts (Reeser et al. 2013). More recently, P. pluvialis has been reported to cause needle loss and shoot dieback in Douglas-fir (Pseudotsuga menziesii [Mirb.] Franco) plantations and has been isolated from Douglas-fir needles from trees with symptoms of premature defoliation akin to Swiss needle cast (SNC) in Oregon and New Zealand (Hansen et al. 2015).

In both radiata pine and Douglas-fir, $P$. pluvialis infection is characterized by the production of olive-colored lesions and black resinous bands on needles followed by accelerated senescence and casting. Based on studies on radiata pine, infection requires damp and cool weather conditions and typically occurs from autumn to early spring (Dick et al. 2014). During this time, different degrees of defoliation can be observed in the field, normally starting at the bottom of the canopy. Little is known about the $P$. pluvialis infection cycle in Douglas-fir, or its impact on tree growth and survival.

Douglas-fir is considered one of the most important tree species in the timber trade worldwide. It is a dominant tree species in the U.S. Pacific Northwest, with remarkable ecological and economic significance. It is the most abundant exotic tree species cultivated in Central Europe (Schmid et al. 2014), and the second most important exotic plantation species in New Zealand, with 110 thousand planted hectares (New Zealand Forest Owners Association 2014). During the last decades, the productivity of Douglas-fir has been reduced by SNC, caused by the widespread fungus Phaeocryptopus gaeumannii (Rohde) Petrak. SNC occurs where Douglas-fir is grown as an exotic species (Boyce 1940; Castaño et al. 2014; Hood 1999; Lanier 1966;

Corresponding author: Mireia Gómez-Gallego;

E-mail: mireia.gomez@scionresearch.com

Accepted for publication 8 March 2017.

@ 2017 The American Phytopathological Society
Merrill and Longenecker 1973; Morton and Patton 1970; Osorio 2007; Temel et al. 2003), and throughout the species' natural range of the Pacific Northwest (Hansen et al. 2000; Hood 1982).

In contrast to RNC on Douglas-fir, the impacts of SNC have been thoroughly described (Hansen et al. 2000; Kimberley et al. 2011; Maguire et al. 2002; Manter et al. 2000, 2003b; Temel et al. 2004). Swiss needle cast causes defoliation and consequent growth reduction with an estimated mean volume growth loss of $23 \%$ in Oregon plantations in 1996 and in severe cases as high as 52\% (Maguire et al. 2002). Defoliation has been shown to be proportional to the number of stomata occluded by pseudothecia of the fungus (Hansen et al. 2000; Manter et al. 2003a). The abscission of the foliage occurs shortly after becoming a carbon sink, which is reached when $25 \%$ of stomata are occluded by pseudothecia (Manter et al. 2003a).

$P$. gaeumannii ascospore dispersal and new infections are facilitated by high humidity and needle wetness (Manter et al. 2005), similar to the conditions in which $P$. pluvialis thrives. $P$. gaeumannii sporulation takes place in spring, spanning the period of flush and expansion of new Douglas-fir foliage (Hood 1999; Stone et al. 2008). Moreover, there is no asexual stage and only one infection cycle occurs each year (Stone et al. 2008). As both SNC and RNC are promoted by high humidity levels in the foliage environment, we encountered difficulties in achieving exclusive $P$. pluvialis infection on Douglas-fir. A detached needle assay applying a dip inoculation with $P$. pluvialis resulted in dual expression of RNC and SNC, demonstrating the unsuitability of this routine inoculation method (Dick et al. 2014).

In previous experiments involving $P$. gaeumannii, protectant fungicides (i.e., chlorothalonil; Manter et al. 2003a, b) have been used to create control plants. However, this fungicide has been used previously to control other Phytophthora diseases (Hamm and Clough 1999; Ratajkiewicz et al. 2016; Sujkowski et al. 1995; Vawdrey et al. 2015). Hence, the study of $P$. pluvialis epidemiology can be biased by chlorothalonil application, and an alternative strategy should be designed. The aim of this study was to devise a procedure to minimize $P$. gaeumannii inoculum in order to reduce the dual disease expression bias currently involved in RNC studies with Douglas-fir. We hypothesized that keeping Douglas-fir plants sheltered from rain, fog, and overhead irrigation during the flushing period and providing drip irrigation instead would reduce leaf wetness to condensation events and hence minimize $P$. gaeumannii spore formation and colonization 
of new foliage. This procedure would yield new foliage with low $P$. gaeumannii abundance for bias-reduced studies of $P$. pluvialis on Douglas-fir.

\section{Materials and Methods}

Phytophthora pluvialis detached needle assay. Zoospore production. Zoospore production was performed as described by Dick et al. (2014). Plugs of agar and mycelium taken from the leading edge of the colonies were flooded with $75 \mathrm{ml}$ of clarified carrot broth (Erwin and Ribeiro 1996) in $500 \mathrm{ml}$ vented flat bottomed flasks (Medi'Ray, New Zealand) and incubated in the dark at $17^{\circ} \mathrm{C}$ for 4 days. The resulting mycelial mats were rinsed thoroughly in a steady stream of deionized water, drained, then reflooded with $75 \mathrm{ml}$ of sterile pond water, and incubated for 3 more days. Zoospore release was induced by cold-shocking the cultures at $4^{\circ} \mathrm{C}$ in the dark for $45 \mathrm{~min}$, followed by exposure at room temperature $\left(21^{\circ} \mathrm{C}\right)$, and by placing cultures on a light box if required. Zoospore concentrations were determined using a hemocytometer, reaching a minimum of $3 \times 10^{3}$ zoospores $/ \mathrm{ml}$. Zoospore suspensions were used within $2 \mathrm{~h}$ of preparation. The isolates used as source of inoculum had been identified using morphological and molecular techniques. The origin of the isolates is given in Table 1.

Needle inoculation. Current-year needles (around 3 months old) were collected from 12 six-year-old open-pollinated Douglas-fir saplings grown in the open in 25 liter growth bags at the Scion nursery (Rotorua, New Zealand) in February 2016 (midsummer). Fifty needles were removed from each of the 12 saplings. Twenty-five needles were treated with $P$. pluvialis zoospore suspensions and the remaining 25 were treated with sterile pond water. In both treatments, five needles were placed vertically, basal end down, in each of five $2 \mathrm{ml}$ microcentrifuge tubes containing $250 \mu \mathrm{l}$ of either zoospore suspension or sterile pond water for a period of $24 \mathrm{~h}$. Afterward, the needles were placed on moistened paper towels in sealed trays and incubated at $17^{\circ} \mathrm{C}$ with a $12 \mathrm{~h}$ photoperiod for 11 days.

After 11 days, total needle length and lesion length, characteristic of the early symptoms of RNC (olive-colored discoloration and black bands, Dick et al. 2014) were recorded, and the percentage of lesioned needle length calculated. All needles were surface sterilized by washing them in $70 \%$ ethanol for $30 \mathrm{~s}$, rinsed in sterile deionized water and dabbed on filter paper, and subsequently placed onto PARP (pimaricin, ampicillin, rifampicin, pentachloronitrobenzene PCNB) agar as described by Jeffers and Martin (1986). Phytophthora colonies were morphologically identified to species (Reeser et al. 2013) by both subculturing in $10 \%$ carrot agar selective media and inducing sporangia production in pond water (Erwin and Ribeiro 1996).

Phaeocryptopus gaeumannii suppression assays. Five of the 6-year-old Douglas-fir saplings grown in the open and thus naturally contained $P$. gaeumannii. They were transferred to sheltered conditions and watered with drip irrigation throughout the sporulation season from November 2015 to February 2016. Another five saplings kept outdoors under natural environmental conditions served as controls.

$P$. gaeumannii pseudothecia density was assessed in 10 currentyear (around 5 months old) and 10 one-year-old needles collected from each sapling on 27 April 2016 following the methods of Manter et al. (2001) with a few modifications. In brief, the number of pseudothecia emerging from 80 to 100 consecutive stomata at the bottom, mid, and upper third of the needle were determined by visually counting (at $135.3 \times$

Table 1. Origin of Phytophthora pluvialis isolates used for Douglas-fir inoculations from the Scion culture collection

\begin{tabular}{lll}
\hline Isolate no. & \multicolumn{1}{c}{ Date collected } & \multicolumn{1}{c}{ Location } \\
\hline NZFS 4171 & 16 July 2015 & Kaingaroa Forest, 1899724, 5713610 \\
NZFS 4172 & 17 July 2015 & Kaingaroa Forest, 1889140, 5706150 \\
NZFS 4175 & 12 August 2015 & Reporoa, 1904572, 5743513 \\
NZFS 4234 & 12 August 2015 & Golden Downs, 1589477, 5398855 \\
NZFS 4267 & 22 September 2015 & Kinleith, 1851803, 5781881 \\
NZFS 4285 & 4 October 2015 & Kinleith, 1860169, 5771033 \\
NZFS 4286 & 4 October 2015 & Kinleith, 1860169, 5771033 \\
\hline
\end{tabular}

total magnification, optical microscope Reichert, Austria) pseudotheciaoccluded and pseudothecia-free stomata in one randomly chosen row of stomata. The pseudothecia density in the adjacent 1-year-old needles was taken as the baseline presence of $P$. gaeumannii in each tree. The pseudothecia density in current-year needles served as a control for the water and zoospore suspension dip inoculations.

A P. pluvialis detached needle was performed in the same way as described above to test the suppression of $P$. gaeumannii (inoculation started on 28 April 2016). Additionally, a detached twig assay was performed. Ten twigs were sampled from each of the 10 saplings and inoculated in $50 \mathrm{ml}$ plastic centrifuge tubes containing either $10 \mathrm{ml}$ of zoospore suspension or sterile pond water. At the end of the experiment, all needles and twigs (stem and needles) from both experiments were assessed for the presence or absence of typical RNC lesions, surface sterilized, and cultured for Phytophthora reisolation and identification, as stated above. One needle per tube from the detached needle assay (10 needles per sapling) was randomly chosen to assess the density of $P$. gaeumannii pseudothecia. Moreover, the presence or absence of typical RNC lesions 4 and 8 days after inoculation was monitored to assess the timing of lesion development in needles from both experiments, and stems from the twig experiment.

Data analysis. Linear mixed effects models were used to test the effects of $P$. pluvialis inoculation in the detached needle assay. The two measured response variables were percentage of lesioned needle length and percentage of $P$. pluvialis isolates of the five needles per tube. Both response variables were logit transformed (R-package car) prior to analysis. 'Tube' was nested within 'sapling' as a random term.

In the $P$. gaeumannii suppression assay, a generalized linear model with a binomial error distribution was used to test the effects of zoospore suspension, water dip, and no treatment control, on average pseudothecia density per sapling as a response variable. The baseline pseudothecia density in 1-year-old needles was included in the model as an offset term.

All analyses were carried out with R Statistical Software version 3.3.0 using the lme (R-package nlme, Pinheiro et al. 2016) and glm functions.

\section{Results}

Phytophthora pluvialis detached needle assay. In the absence of SNC suppression, both the water control and the needles inoculated with $P$. pluvialis produced a similar percentage of lesioned needle length 11 days after inoculation. On average, both treatments yielded around $7 \%$ of lesioned needle length (Fig. 1a). Lesions in the water control and $P$. pluvialis-treated needles were similar, presenting as pale olive discoloration and occasionally black marks. Eleven days after inoculation, $P$. pluvialis was recovered from $35 \%$ of the pathogen-treated needles while no isolates were derived from the uninoculated control plants (Fig. 1b). P. gaeumannii pseudothecia were observed in both water control and $P$. pluvialis-infected needles (data not shown).

Phaeocryptopus gaeumannii suppression assays. Saplings grown under sheltered conditions using drip irrigation to minimize needle wetness showed significantly less SNC infection compared with unsheltered plants. This effect varied with the inoculation treatment (dry control, water control, or $P$. pluvialis inoculation) resulting in a significant interaction $(\mathrm{L}=51.07, \mathrm{DF}=2, P<0.0001)$. Current-year needles from sheltered saplings presented less than $3 \%$ of their stomata blocked by pseudothecia, whereas those from unsheltered saplings had around $42 \%$ of their stomata occluded by pseudothecia (Fig. 2).

Dry controls yielded significantly less pseudothecia than those receiving dip inoculations (water, $P$. pluvialis), irrespective of whether they were growing under sheltered or unsheltered conditions (Fig. 2). Further, there was no difference in the development of SNC between the saplings inoculated with water or zoospore solution (Fig. 2).

Both the detached needle and detached twig assays yielded visible needle lesions, but $P$. pluvialis isolates were only obtained from inoculated needles and twigs. Although no stem lesions were observed at all, surface-sterilized stems from sheltered and unsheltered plants 
yielded $P$. pluvialis isolates, confirming the presence of the pathogen (Table 2).

Visible needle lesions developed more rapidly in the detached needle assay compared with twig inoculation. In the detached needle assay, about $85 \%$ of those needles that had produced lesions at the end of the experiment were symptomatic within 4 days after inoculation. By contrast, in the detached twig assay, only $0.2 \%$ of the lesioned needles recorded at the end of the experiment were symptomatic 4 days after inoculation, increasing to $95 \%$ on day eight.

\section{Discussion}

The study of the complex plant-pathogen interaction between $P$. pluvialis and Douglas-fir presents great challenges to researchers. The key difficulties lie in the dual disease expression of RNC and SNC in areas where both pathogens co-occur and the inefficacy of visual symptoms alone for disease differentiation. Here, we tested whether avoidance of leaf wetness throughout the P. gaeumannii sporulation period would suppress SNC expression and enable inoculation with $P$. pluvialis without the confounding effects of $P$. gaeumannii.

Our study showed that diagnosis solely based on visual symptoms is not able to distinguish SNC from RNC (Fig. 1a). Pseudothecia density has been previously well correlated to chlorosis and needle retention (Winton et al. 2003). Moreover, the blockage of stomata by $P$. gaeumannii is likely to physically impede $P$. pluvialis infection.
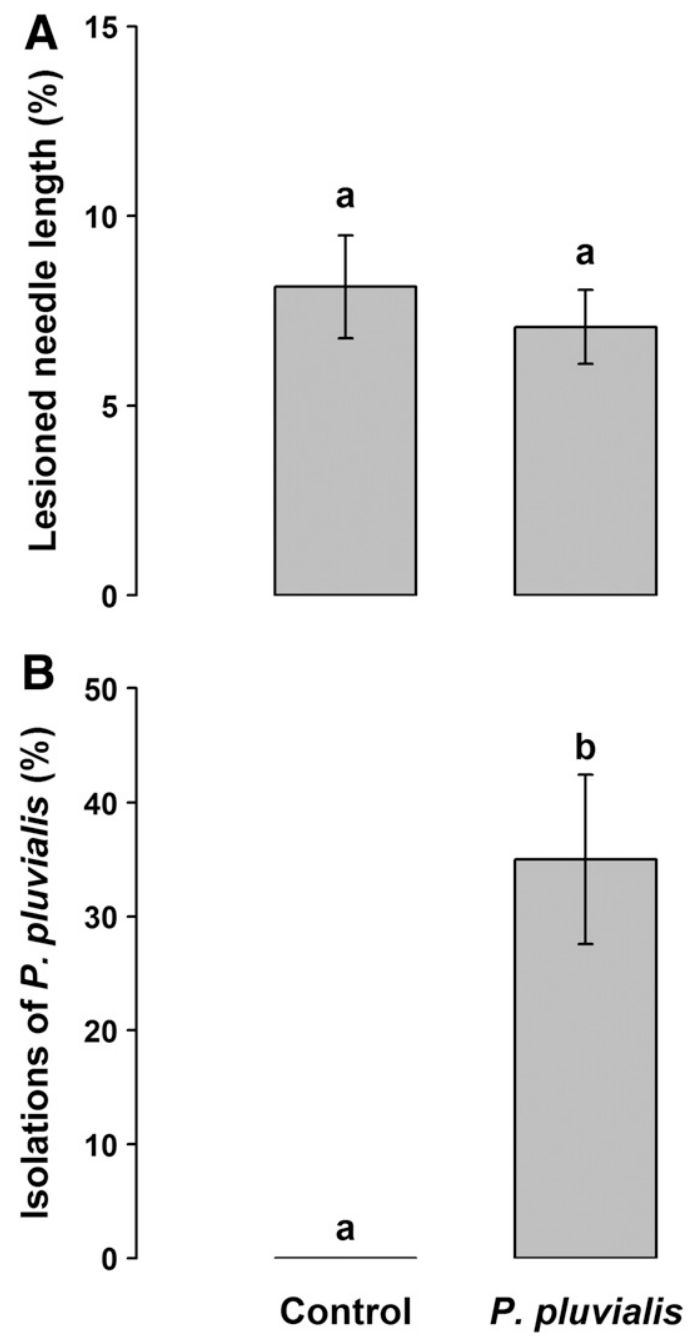

Fig. 1. A, Lesioned needle length (percentage of the total needle length showing symptoms of infection) in detached Douglas-fir needles dipped into water (control) or dip inoculated with Phytophthora pluvialis zoospore solution ( $P$. pluvialis); and $\mathrm{B}$, percentage of isolation attempts yielding $P$. pluvialis in the two treatments. Different lower case letters indicate statistically significant differences within groups at $\alpha=0.05$ (posthoc comparison using Tukey contrasts). Means $\pm \mathrm{SE}, n=12$.
Microscope-aided counting of these fruiting bodies provided a simple and direct means of $P$. gaeumannii quantification. In contrast, the lack of such easily discernible structures makes the quantification of $P$. pluvialis infection in Douglas-fir much more difficult.

The earlier onset of symptoms in detached needles compared with the needles in the twig assay suggests greater rate of infection in more rapidly senescing tissues. This increased susceptibility may result from accelerated biochemical changes and tissue dehydration in detached needles. In contrast, physiological deterioration is likely to proceed more slowly in needles still connected to stems, resulting in prolonged defense to infection as suggested by the delayed emergence of symptoms in the twig assay. Therefore, the use of detached twigs in inoculation studies more realistically represents the infection process and the physiological changes taking place in planta.

Irrespective of $P$. pluvialis inoculation, our detached needle experiment demonstrated that not accounting for the presence of $P$. gaeumannii will result in SNC expression. Here this caused $42 \%$ stomatal occlusion exceeding the $25 \%$ threshold of needle cast (Manter et al. 2003a).

Our findings highlight the importance of minimizing $P$. gaeumannii sporulation through the prevention of needle surface wetting by sheltering and drip watering plants from spring to summer to allow bias-reduced epidemiological studies of $P$. pluvialis in Douglas-fir. While chlorothalonil fungicide has been used to create SNC-free control plants in previous studies (Manter et al. 2003a, b), such an approach may also impact Phytophthora development, as it has been used before to control other Phytophthora diseases (Hamm and Clough 1999; Ratajkiewicz et al. 2016; Sujkowski et al. 1995; Vawdrey et al. 2015). With the 'dry leaf' approach presented here, the effects of $P$. pluvialis on the physiology of current-year needles can be investigated without confounding. Extrapolation to the
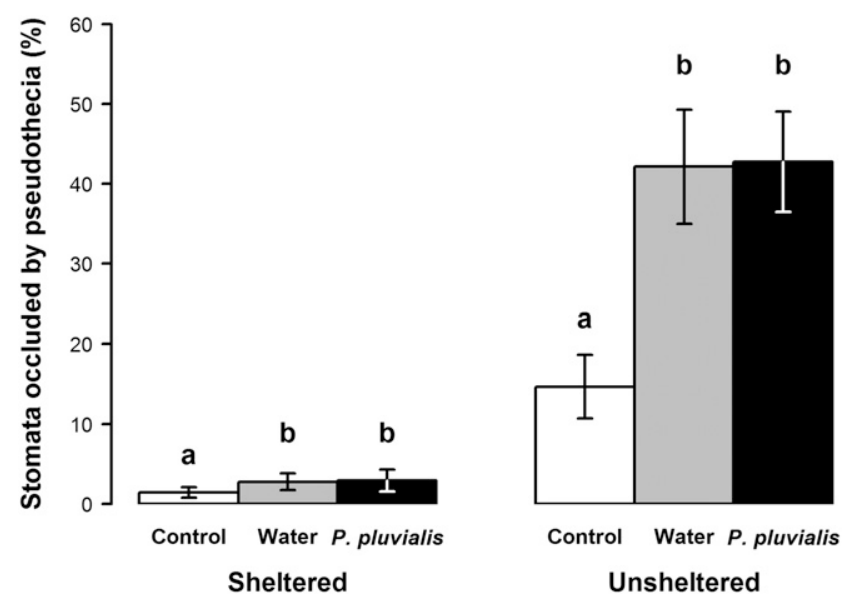

Fig. 2. Phaeocryptopus gaeumannii pseudothecia density (percentage of stomata occluded by pseudothecia) in needles of Douglas-fir sheltered and unsheltered plants, under different inoculation treatments: no inoculation (control), dip inoculation with water (water), and dip inoculation with Phytophthora pluvialis zoospore solution. Different lower case letters indicate statistically significant differences within groups at $\alpha=0.05$ (posthoc comparison using Tukey contrasts). Means $\pm \mathrm{SE}, n=10$.

Table 2. Presence (+) / absence (-) of lesions and P. pluvialis isolations in the detached needle and detached twig assays for sheltered and unsheltered plants

\begin{tabular}{|c|c|c|c|c|}
\hline & \multicolumn{2}{|c|}{ Detached needles } & \multicolumn{2}{|c|}{ Detached twigs } \\
\hline & Sheltered & Unsheltered & Sheltered & Unsheltered \\
\hline $\begin{array}{l}\text { Presence of needle } \\
\text { lesions }\end{array}$ & + & + & + & + \\
\hline $\begin{array}{l}\text { Presence of stem } \\
\text { lesions }\end{array}$ & & & - & - \\
\hline $\begin{array}{l}\text { P. pluvialis isolates } \\
\text { from needles }\end{array}$ & + & + & + & + \\
\hline $\begin{array}{l}\text { P. pluvialis isolates } \\
\text { from stem }\end{array}$ & & & + & + \\
\hline
\end{tabular}


whole-plant level requires a more refined approach because of the presence of $P$. gaeumannii in previous-year needles. Based on our approach, it might be assumed that a reduction in abundance of this preexisting fungal inoculum would occur only gradually over several years of growth under sheltered conditions. For multiyear trials assessing infection and physiological impacts across multiple needle age classes, plants should be sourced free of $P$. gaeumannii and grown under sheltered conditions in the absence of inoculum.

While the interaction between the two pathogens is an issue in laboratory inoculation studies, we speculate that, under field conditions, infection of the new season's growth by $P$. pluvialis and P. gaeumannii may be separated temporally. This would imply that defoliation events caused by RNC may have previously been reported as SNC contributing to unseasonal and extended periods of needle casting. The implications for forest pathology research, monitoring, and disease management are significant given the pronounced differences in pathogen taxonomy, epidemiology, and potential management. Differentiating the impact of RNC will require a better understanding of the interplay between both pathogens and calls for targeted diagnosis and monitoring throughout the year. At this stage, informative diagnosis requires a combination of microscopy and molecular tools to address infection by $P$. pluvialis and $P$. gaeumannii. Future studies may benefit from incorporating quantitative PCR measurements to directly quantify both pathogens in parallel. Such assays along with RNA sequence analyses could help disentangle the temporal impacts of both pathogens and their interaction, respectively. Whether $P$. pluvialis triggers needle cast in Douglas-fir at similar levels to SNC or those reported for RNC in radiata pine remains to be shown by extended epidemiological studies using the 'dry leaf' approach put forward here.

\section{Acknowledgments}

The authors are indebted to The Forest Owners Association, New Zealand, and Ministry of Business Innovation and Employment (C04X1305), New Zealand, who provided the funding for this work. Further, the authors would like to thank C. Banham and P. Panda for assistance with inoculum preparation, and I. Hood for helpful discussions around SNC epidemiology. We also thank the three anonymous reviewers whose comments helped us to improve earlier versions of this manuscript.

\section{Literature Cited}

Boyce, J. S. 1940. A needle cast of Douglas-fir associated with Adelopus gaeumannii. Phytopathology 30:649-659.

Castaño, C., Colinas, C., Gómez, M., and Oliva, J. 2014. Outbreak of Swiss needle cast caused by the fungus Phaeocryptopus gaeumannii on Douglas-fir in Spain. New Dis. Rep. 29:19.

Dick, M. A., Williams, N. M., Bader, M. K. F., Gardner, J. F., and Bulman, L. S. 2014. Pathogenicity of Phytophthora pluvialis to Pinus radiata and its relation with red needle cast disease in New Zealand. N. Z. J. For. Sci. 44:6.

Erwin, D. C., and Ribeiro, O. K. 1996. Phytophthora diseases worldwide. APS Press, St Paul, MN.

Hamm, P. B., and Clough, G. H. 1999. Comparison of application methods on deposition and redistribution of chlorothalonil in a potato canopy and potential for control of late blight. Plant Dis. 83:441-444.

Hansen, E., Reeser, P., Sutton, W., Gardner, J., and Williams, N. 2015. First report of Phytophthora pluvialis causing needle loss and shoot dieback on Douglas-fir in Oregon USA and New Zealand. Plant Dis. 99:727.

Hansen, E. M., Stone, J. K., Capitano, B. R., Rosso, P., Sutton, W., and Winton, L. 2000. Incidence and Impact of Swiss Needle Cast in Forest Plantations of Douglas-fir in Coastal Oregon. Plant Dis. 84:773-778.

Hood, I. A. 1982. Phaeocryptopus gaeumannii on Pseudotsuga menziesii in Southern British Columbia. N. Z. J. For. Sci. 12:415-424.
Hood, I. A. 1999. Swiss needle cast of Douglas-fir. A review from a New Zealand perspective. New Zealand Forest Research Institute, Rotorua, New Zealand.

Jeffers, S. N., and Martin, S. B. 1986. Comparison of two media selective for Phytophthora and Pythium species. Plant Dis. 70:1038-1043.

Kimberley, M. O., Hood, I. A., and Knowles, R. L. 2011. Impact of Swiss needle cast on growth of Douglas-fir. Phytopathology 101:583-93.

Lanier, L. 1966. Les maladies cryptogamiques du Douglas en France. Rev. For. Fr. 18:247-265.

Maguire, D. A., Kanaskie, A., Voelker, W., Randy, J., and Johnson, G. 2002 Growth of young Douglas-fir plantations across a gradient in Swiss needle cast severity. West. J. Appl. For. 17:86-95.

Manter, D. K., Bond, B. J., Kavanagh, K. L., Rosso, P. H., and Filip, G. M. 2000. Pseudothecia of Swiss needle cast fungus, Phaeocryptopus gaeumannii, physically block stomata of Douglas-fir, reducing $\mathrm{CO}_{2}$ assimilation. New Phytol. 148:481-491.

Manter, D. K., Bond, B. J., Kavanagh, K. L., Stone, J. K., and Filip, G. M. 2003a. Modelling the impacts of the foliar pathogen, Phaeocryptopus gaeumannii, on Douglas-fir physiology: net canopy carbon assimilation, needle abscission and growth. Ecol. Modell. 164:211-226.

Manter, D. K., Kelsey, R. G., and Stone, J. K. 2001. Quantification of Phaeocryptopus gaeumannii colonization in Douglas-fir needles by ergosterol analysis. For. Pathol. 31:229-240.

Manter, D. K., Reeser, P. W., and Stone, J. K. 2005. A climate-based model for predicting geographic variations in Swiss needle cast severity in the Oregon coast range. Phytopathology 95:1256-1265.

Manter, D. K., Winton, L. M., Filip, G. M., and Stone, J. K. 2003b. Assessment of Swiss needle cast disease: Temporal and spatial investigations of fungal colonization and symptom severity. J. Phytopathol. 151:344-351.

Merrill, W., and Longenecker, J. 1973. Swiss needle cast of Douglas-fir in Pennsylvania. Plant Dis. Rep. 57:984.

Morton, H. L., and Patton, R. F. 1970. Swiss Needle Cast of Douglas-fir in the Lake States. Plant Dis. Rep. 54:612-616.

New Zealand Forest Owners Association. 2014. New Zealand Plantation Forest Industry. Facts and figures. Ministry for Primary Industries, Wellington, New Zealand.

Osorio, O. M. 2007. Detección del hongo defoliador Phaeocryptopus gaeumannii en plantaciones de Pseudotsuga menziesii de Valdivia, Chile. Bosque (Valdivia) 28:69-74.

Pinheiro, J., and Bates, D., DebRoy, S., Sarkar, D., and R Core Team. 2016. nlme: Linear and Nonlinear Mixed Effects Models. R package version 3.1-128, https://cran.r-project.org/web/packages/nlme/index.html.

Ratajkiewicz, H., Kierzek, R., Raczkowski, M., Holodynska-Kulas, A., Lacka, A., Wojtowicz, A., and Wachowiak, M. 2016. Effect of the spray volume adjustment model on the efficiency of fungicides and residues in processing tomato. Span. J. Agric. Res. 14:e1007.

Reeser, P., Sutton, W., and Hansen, E. 2013. Phytophthora pluvialis, a new species from mixed tanoak-Douglas-fir forests of western Oregon, U.S.A. N. Am. Fungi 8:1-8.

Schmid, M., Pautasso, M., and Holdenrieder, O. 2014. Ecological consequences of Douglas-fir (Pseudotsuga menziesii) cultivation in Europe. Eur. J. For. Res. 133:13-29.

Stone, J. K., Capitano, B. R., and Kerrigan, J. L. 2008. The histopathology of Phaeocryptopus gaeumannii on Douglas-fir needles. Mycologia 100:431-444.

Sujkowski, L. S., Fry, B. A., Power, R. J., Goodwin, S. B., Peever, T. L., Hamlen, R. A., and Fry, W. E. 1995. Sensitivities of Mexican isolates of Phytophthora infestans to chlorothalonil, cymoxanil and metalaxyl. Plant Dis. 79:1117-1120.

Temel, F., Johnson, G. R., and Stone, J. K. 2004. The relationship between Swiss needle cast symptom severity and level of Phaeocryptopus gaeumannii colonization in coastal Douglas-fir (Pseudotsuga menziesii var. menziesii). For. Pathol. 34:383-394.

Temel, F., Stone, J. K., and Johnson, G. R. 2003. First report of Swiss needle cast caused by Phaeocryptopus gaeumannii on Douglas-fir in Turkey. Plant Dis. 87: 1536.

Vawdrey, L. L., Male, L., and Grice, K. R. E. 2015. Field and laboratory evaluation of fungicides for the control of Phytophthora fruit rot of papaya in far north Queensland, Australia. Crop Prot. 67:116-120.

Winton, L. M., Manter, D. K., Stone, J. K., and Hansen, E. M. 2003. Comparison of Biochemical, Molecular, and Visual Methods to Quantify Phaeocryptopus gaeumannii in Douglas-fir Foliage. Phytopathology 93:121-126. 